\title{
STUDIES OF MONOMER IMPREGNATION AND POLYMERIZED "IN-SITU" IN WOOD USING DYNAMIC MECHANICAL THERMAL ANALYZER (DMTA)
}

\author{
S. Hamdan*, Y.L. Liew \\ Faculty of Engineering, Universiti Malaysia Sarawak, 94300 Kota Samarahan
}

\section{Z.A. Talib}

Faculty of Science, Universiti Putra Malaysia, Serdang, 43400 Selangor

Received 18 December 2006

\begin{abstract}
Some tropical hardwoods (acacia mangium, madhuca utilis, dacrydium spp., dipterocarpus spp., dyera costulata, shorea spp., shorea gibbosa, shorea macrophylla, endospermum diadenum, cratoxylum arborescens) are selected and impregnated with methyl methacrylate (MMA) and polymerized "in-situ" by using catalyst-heat technique. Treatability of the wood as determined from the fractional volumetric retentions of monomer i.e. fraction of voids filled by the impregnant showed that the mean retention range from $15.03 \%$ (acacia mangium) to $56.59 \%$ (cratoxylum arborescens). The penetration of monomer evaluated using ultrasonic wave showed that the treated wood had higher velocities which indicate significant increase in density. This paper deals with the viscoelastic relaxation of polymerized treated wood. The efficiency of monomer as a plasticizer is studied through the temperature dependence of the storage modulus $\left(\mathrm{E}^{\prime}\right)$ and loss tangent $(\tan \delta)$ of treated and untreated wood by dynamic mechanical thermal analysis (DMTA) over a temperature of -100 to $200^{\circ} \mathrm{C}$. $\mathrm{E}^{\prime}$ decrease with temperature, and as the maximum mechanical damping develop, the glass transition temperature $\left(\mathrm{T}_{\mathrm{g}}\right)$ of plasticized wood decrease with the plasticizer content.
\end{abstract}

Keywords: loss tangent ( $\tan \delta$ ), storage modulus ( $\left.\mathrm{E}^{\prime}\right)$, treatability and ultrasonic velocity.

\section{INTRODUCTION}

Wood is a renewable material. It is the most fascinating materials because of its complex structure and its wide application. There are two classes of wood used in the industries namely hardwood and softwood. Some hardwoods however, are softer than some of the softwoods and vice-versa. Structural wood has many natural deficiencies, such as poor dimensional stability and high moisture adsorption. Moisture adsorption is of high concern because fungi will attack wood if moisture content (MC) changes are higher than 20\%, [1,2]. Moisture adsorptions occur to a piece of wood for construction and even happen to living trees. In tropical countries, these effects are more pronounced due to excessive exposure to sunlight and high hygroscopic. Wood polymerization can reduce these deficiencies and prolong the useful life of woods.

\footnotetext{
* Corresponding author e-mail: hsinin@feng.unimas.my
} 
In recent years, the application of chemical and physical principles to improve wood properties had been studied. Wood treatment introduced between 1930 to 1960 included acetylation of the hydroxyl group, cross-linking of the cellulose with formaldehyde, ethylene oxide addition to the hydroxyl group, ozonolysis and etc. In early 1960, another class of chemicals containing one or more double bonds called vinyl type monomers is introduced to perform wood treatment. These vinyl type monomers can polymerize into solid polymer by means of free radical catalysts [8]. Examples of vinyl monomers are methyl methacrylate (MMA), styrene, vinyl chloride and etc [4]. Different vinyl monomers have been used to produce wood polymers since the past 35 years [3]. MMA is the preferred vinyl monomer.

When heat of polymerization is released quickly in wood-monomer composite, high temperature will increase the vapor pressure of the moisture in the cell walls and as a results moisture drives out of the wood. Volume changes of the cell wall due to shrinkage and distortion of the original shape caused the changes of the dimensions. Monomer penetration can also be determined by comparing the velocity of the pulse traveling in the treated and untreated woods. It is expected that the ultrasonic velocity will be higher in high densities material since the higher void volume of the material will delay the time for the pulses to travel through the material. By comparing the ultrasonic velocities of treated and untreated woods in this experimental study, the effectiveness of the MMA penetrated into the wood species and the treatability of different wood species can be determined.

The dry and clear wood has unique physical properties i.e. high tensile, bending and compression strength, high impact resistance and hardness per unit length whereas for the wood polymer composite (WPC), the physical properties depends on the permeability and the type of the wood species being treated [9]. According to Meyer, the void volume of sapwood and heartwood for most species are the same. It is expected that the polymer fill in the wood to the same extent and therefore WPC or plasticized wood will have improved physical properties and dimensional stability compared with natural wood. The objectives of this works are to determine the capability of Methyl Metha Acrylate (MMA) applied to wood in monomer form and polymerized "in-situ" to penetrate the wood cells utilizing dynamic mechanical thermal analysis (DMTA).

DMTA is applied to study the effect of storage modulus (log E') and loss tangent $(\tan \delta)$ of the treated woods with temperature. With DMTA, i.e. mechanical test, molecules in woods interacted with mechanical stress. Normally all molecular relaxation process are detected using this technique. Data from the DMTA are displayed as graphs of log E' and $\tan \delta$ versus temperature $\mathrm{T}\left({ }^{\circ} \mathrm{C}\right)$. From the data, the changes in $\log \mathrm{E}$ ' gave various state of molecular motion, for e.g. molecular relaxation at the glass transition temperature $\left(\mathrm{T}_{\mathrm{g}}\right)$, and secondary molecular relaxation can also be measured quantitatively as the temperature is scanned.

\section{MATERIALS AND METHODS}

For the impregnation test the wood in green condition are sawn into specimens of $3.0 \mathrm{~cm}(\mathrm{~L}) \times$ $2.0 \mathrm{~cm}(\mathrm{R}) \times 0.5 \mathrm{~cm}(\mathrm{~T})$ and air-dried. The weight and dimension of the air-dried specimens are taken and then oven-dried to constant weight at $105^{\circ}$. A vacuum of less than $5 \mathrm{~mm} \mathrm{Hg}$ is developed for 30 minutes over the oven-dried specimens to evacuate the pores. After the evacuation process MMA monomer containing 2\% benzyl peroxide catalyst and $5 \%$ ethylene glycol dimetha acrylate cross-linker is added. Air is flowed to the chamber and a positive pressure of $0.4 \mathrm{MPa}$ is applied using nitrogen gas for 8 hours. After that the specimens are removed from the chamber. The excess free impregnant is wiped and the specimens weighed immediately to determine the average monomer uptake (equation 2.1) [5]. 


$$
V_{m}=\left(\frac{m_{C}}{m_{W}}-1\right) \frac{Q_{W}}{Q_{m}}
$$

With

$$
\begin{aligned}
& V_{m}=\text { volume fraction of impregnant } \\
& m_{C}=\text { mass of impregnated material } \\
& m_{W}=\text { oven-dried mass of the wood prior to impregnation } \\
& Q_{W}=\text { density of wood based on oven-dried mass and volume } \\
& Q_{m}=\text { density of impregnant }
\end{aligned}
$$

The impregnated specimens are then wrapped in aluminium foil and sealed to minimize the loss of monomer by evaporation. The polymerization is done at $65^{\circ} \mathrm{C}$ for 24 hours. The specimens are again oven-dried at $105^{\circ}$ for 48 hours after polymerization is completed. The treatability of the woods are more convenient to be expressed by the retention of the monomer. The polymerized specimens are measured and weighed to determine the monomer retention (equation 2.2 [6] and equation 2.3 [7]).

$$
\begin{aligned}
& F=\frac{V_{m}}{V_{V}} \\
& V_{V}=1-\frac{Q_{W}}{Q_{W S}}
\end{aligned}
$$

With $\quad F=$ retention of the monomer

$$
\begin{aligned}
& V_{v}=\text { void volume fraction of the unimpregnated wood } \\
& Q_{W S}=\text { density of the cell wall material assumed to be } 1.54 \mathrm{gcm}^{-3}
\end{aligned}
$$

Monomer penetrations are also determined from the ultrasonic pulse by comparing the velocity of pulse travelling in the treated and untreated woods samples. High velocity indicated less voids in the samples. The experiment was done using the Portable Ultrasonic Non Destructive Digital Indicating Tester (PUNDIT) at a frequency of $54 \mathrm{kHz}$ (C.N.S. Electronics Ltd, London, England). The velocity is calculated by using equation 2.4 [Guideline of PUNDIT Tester] below:

$$
\text { Pulse Velocity, } V_{U}=\frac{\text { Path Length, } L}{\text { Transit Time, } t}
$$

In this study, the Perkin Elmer dynamic mechanical thermal analyzer (PE-DMTA) had been used. All results are from the same running conditions i.e. at $10 \mathrm{~Hz}$ frequency, $\times 4$ strains and $2^{\circ} \mathrm{C} \mathrm{min}^{-1}$ temperature rise. The rectangular samples dimension are $10 \mathrm{~mm}(\mathrm{~L}) \times 2 \mathrm{~mm}(\mathrm{R}) \times 7.5$ $\mathrm{mm}(\mathrm{T})$ and are tested using dual-cantilever bending mode on a standard bending head. The chamber surroundings the samples provides simple thermal scan at various frequencies for temperature ranging from -100 to $200^{\circ} \mathrm{C}$.

\section{RESULTS AND DISCUSSIONS}

Figure 1 showed that the wood species gained different level of MMA retention. Generally, the results showed that all the species are treatable as shown by the non-zero percentage of mean retention $(\% \mathrm{~F})$. However the levels of treatability of the species are different from one to another. The higher $\% \mathrm{~F}$ indicates that the wood samples are easily treated and vice versa. The 
highest $\% \mathrm{~F}$ is gained by cratoxylum arborescens $(56.59 \%)$ and the lowest is acacia mangium $(15.03 \%)$.

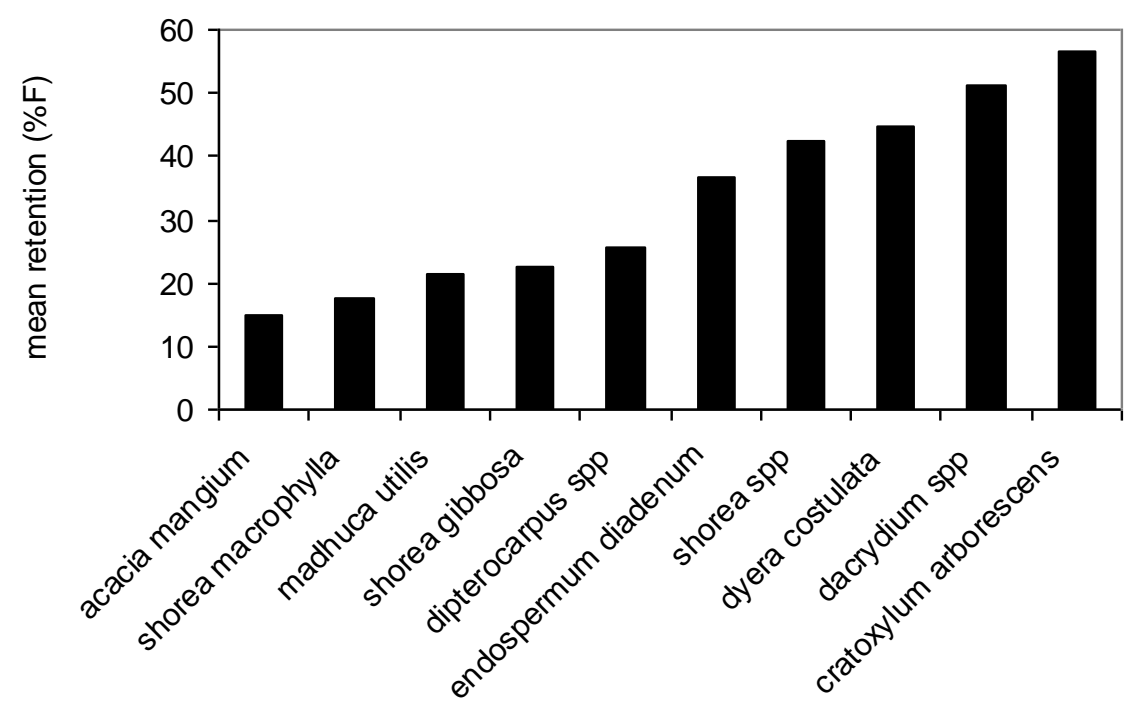

Fig. 1: Histogram of mean retention (\%F) of MMA in treated wood.

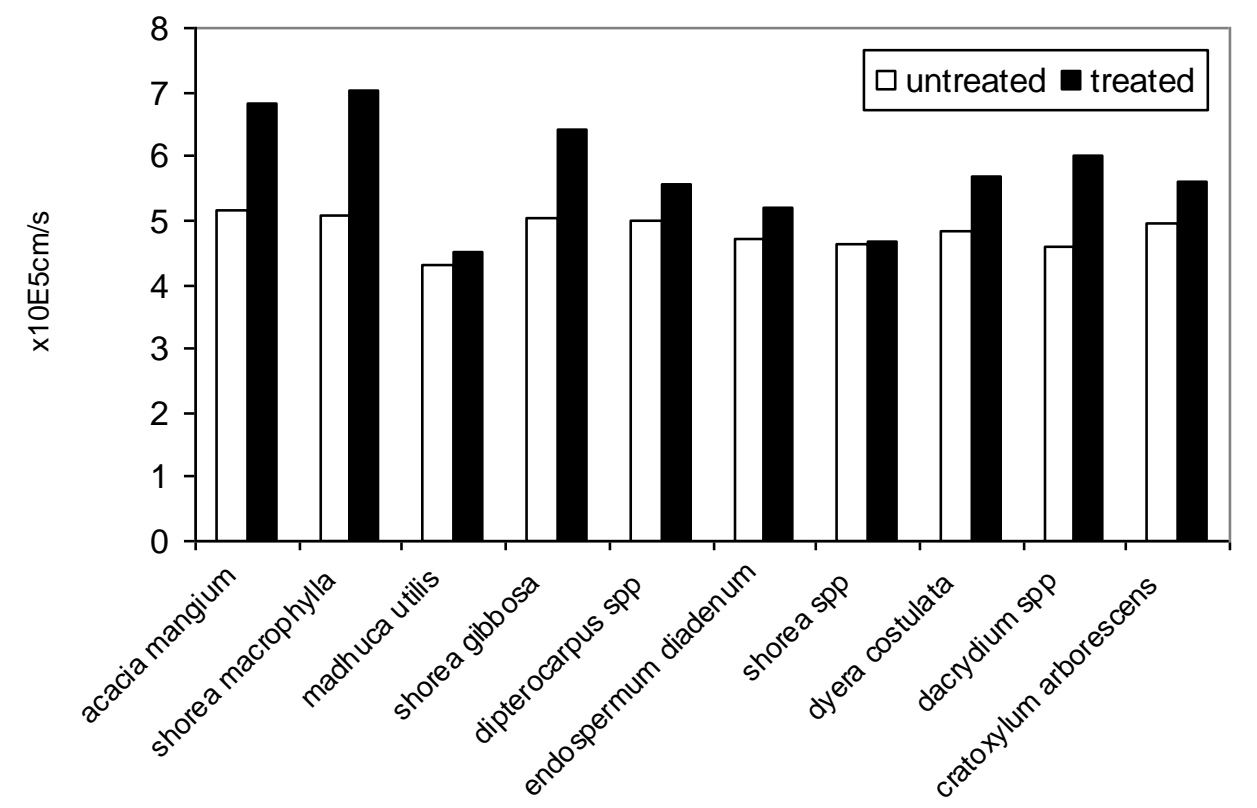

Fig. 2: Histogram of ultrasonic velocity for treated and untreated wood in longitudinal direction.

MMA treatment increased the density of wood since the monomer will polymerize in the void volume of the wood. Figures 2 and 3 showed the histogram of ultrasonic velocity for treated and untreated wood in longitudinal and radial direction respectively. The ultrasonic wave in both direction showed that the treatment have significantly increased the density of the wood. 
DMTA testing data are displayed as graphs of $\log \mathrm{E}^{\prime}$ and $\tan \delta$ versus temperature. Figures 4 13 illustrates the $\mathrm{E}^{\prime}$ and tan $\delta$ along the grain at $10 \mathrm{~Hz}$ as a function of temperature for treated and untreated specimen. The introduction of MMA may reduce the cohesive forces between the main chain and thus the modulus decreased and the loss tangent increased remarkably. The difference of the value of $\tan \delta$ is probably due to the different anatomical structure of wood.

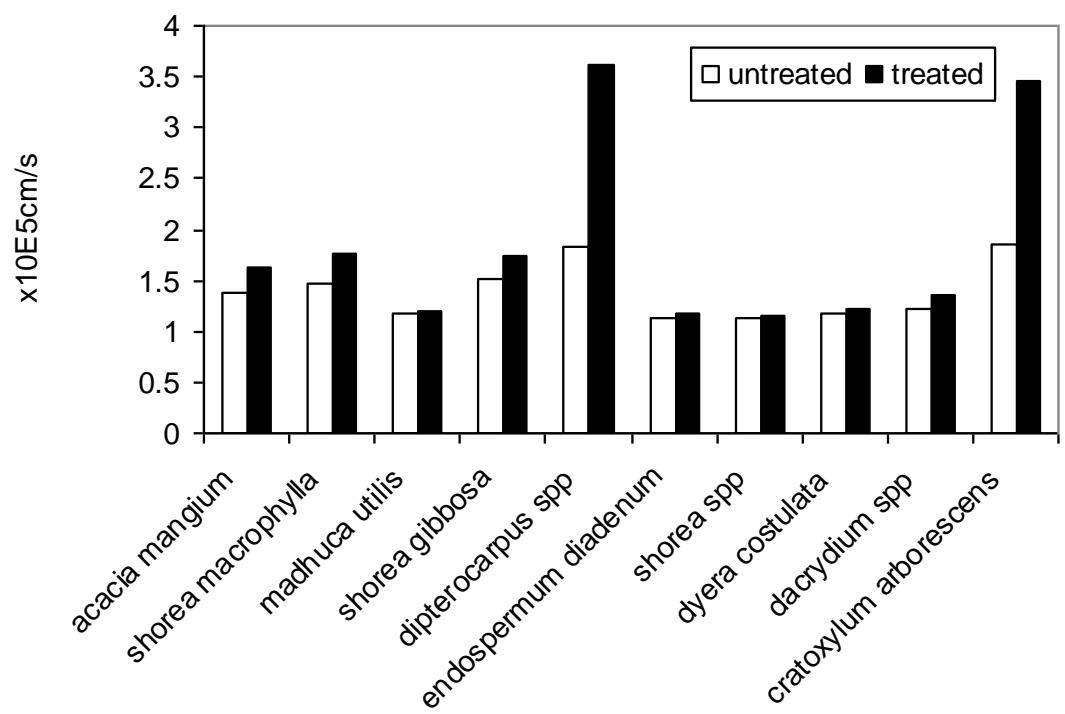

Fig. 3: Histogram of ultrasonic velocity for treated and untreated wood in radial direction.
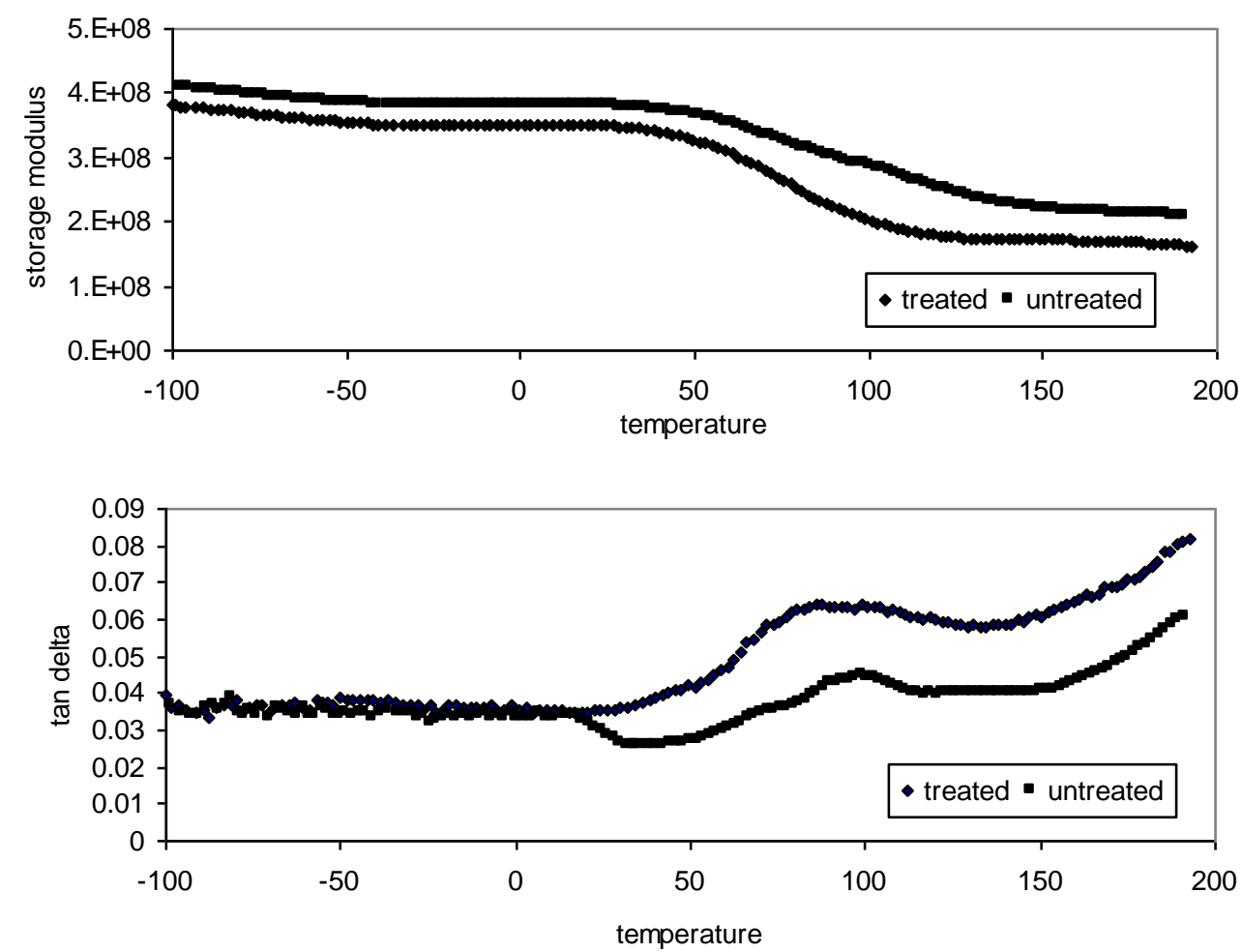

Fig. 4: Storage modulus and tan delta versus temperature for acacia mangium. 

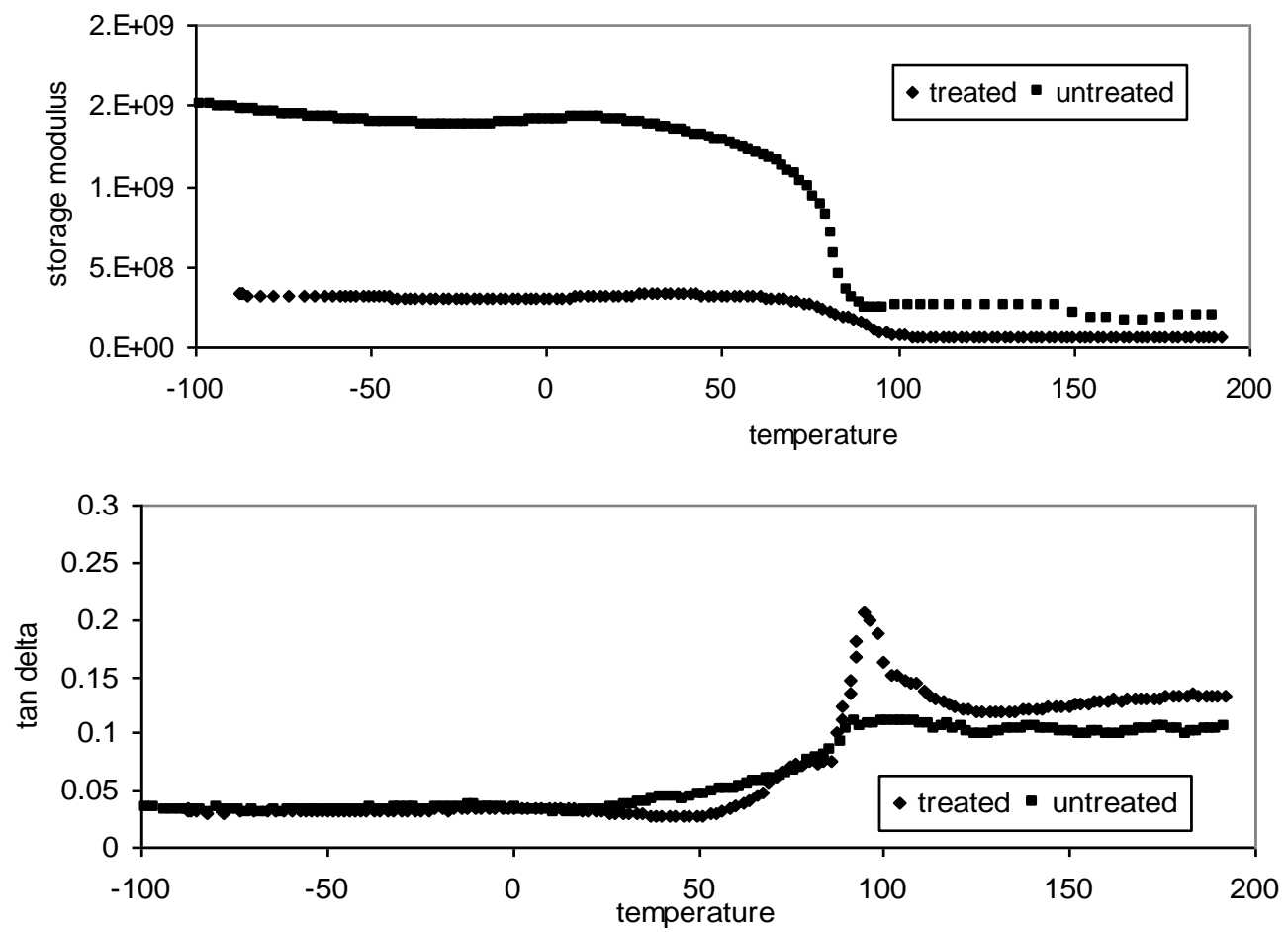

Fig. 5: Storage modulus and tan delta versus temperature for shorea macrophylla.
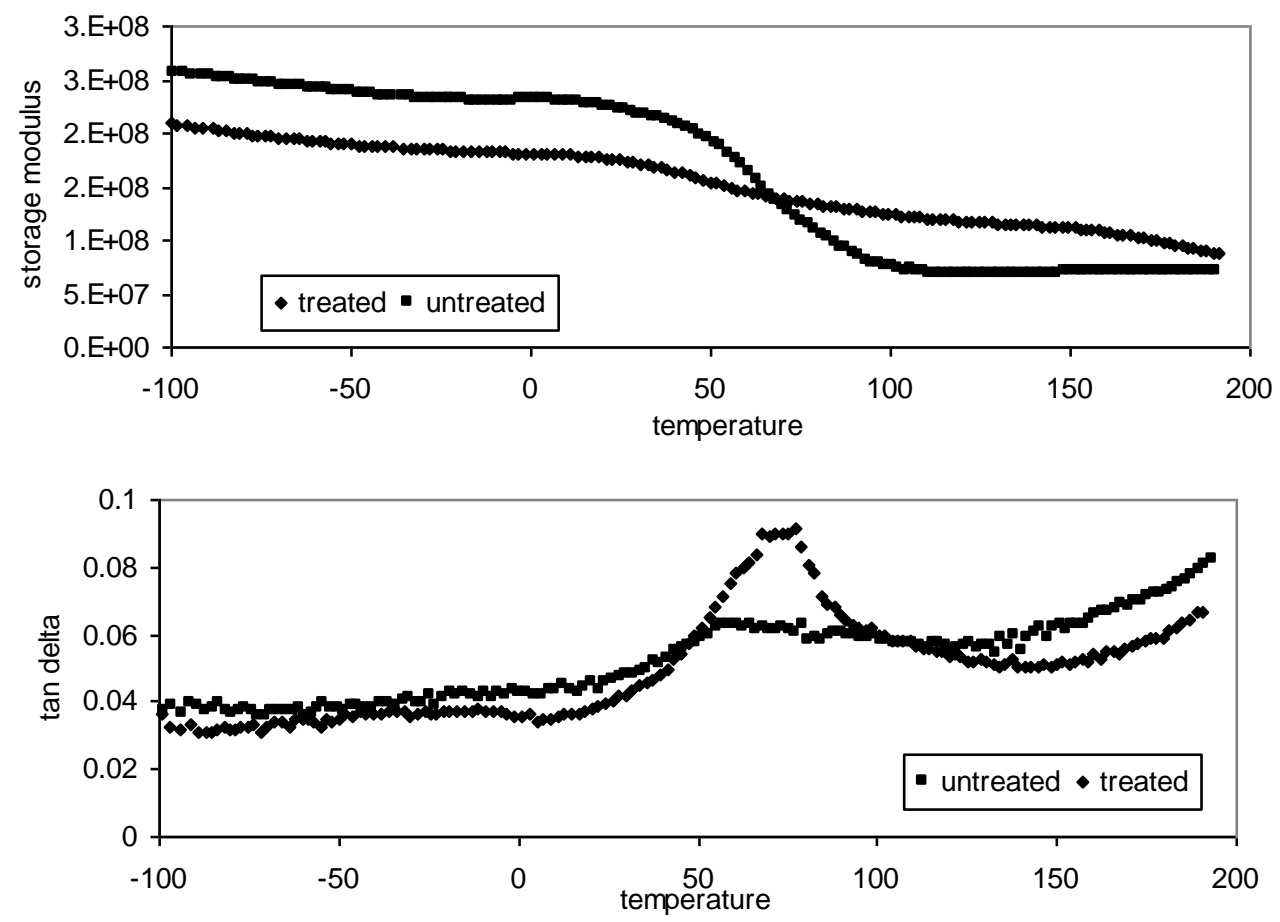

Fig. 6: Storage modulus and tan delta versus temperature for madhuca utilis. 

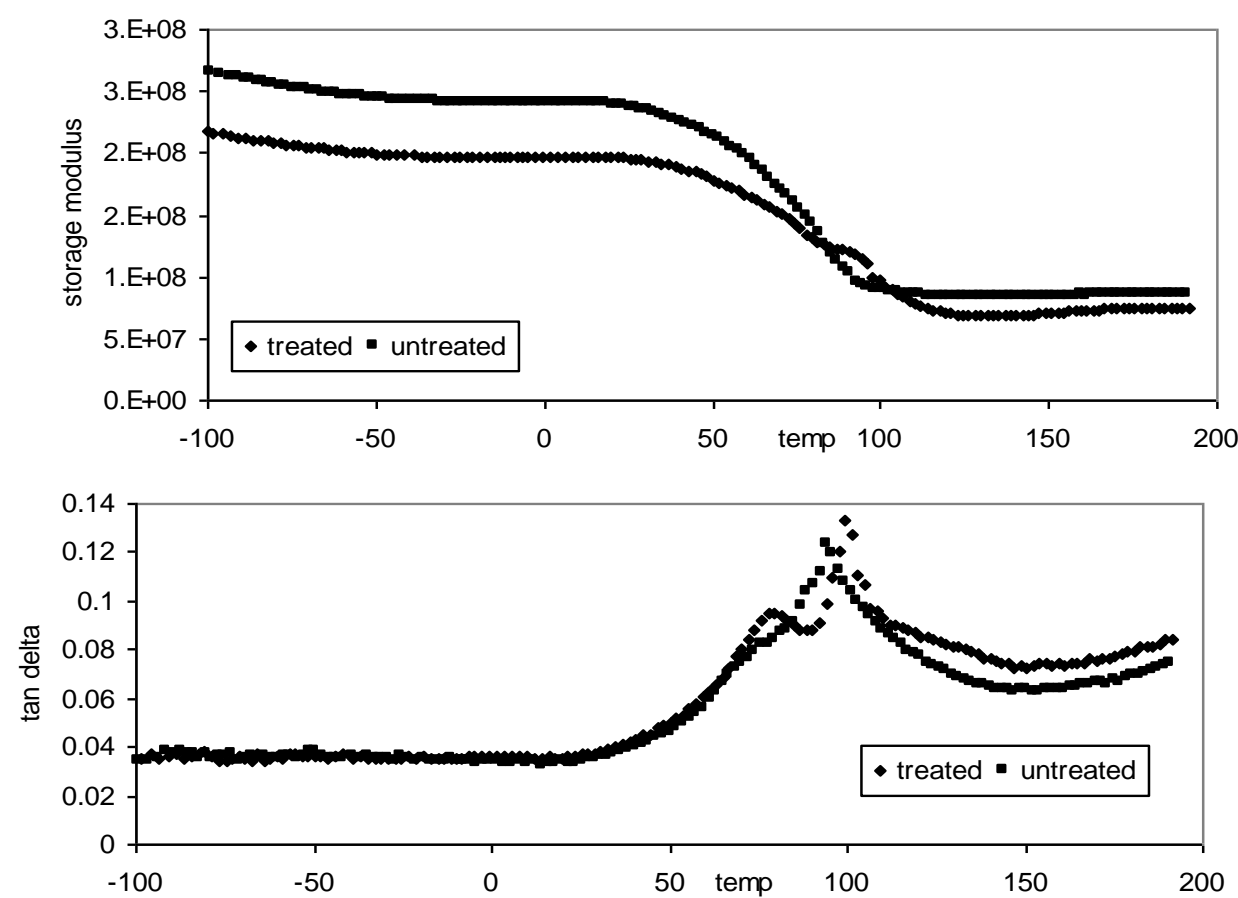

Fig. 7: Storage modulus and tan delta versus temperature for shorea gibbosa.
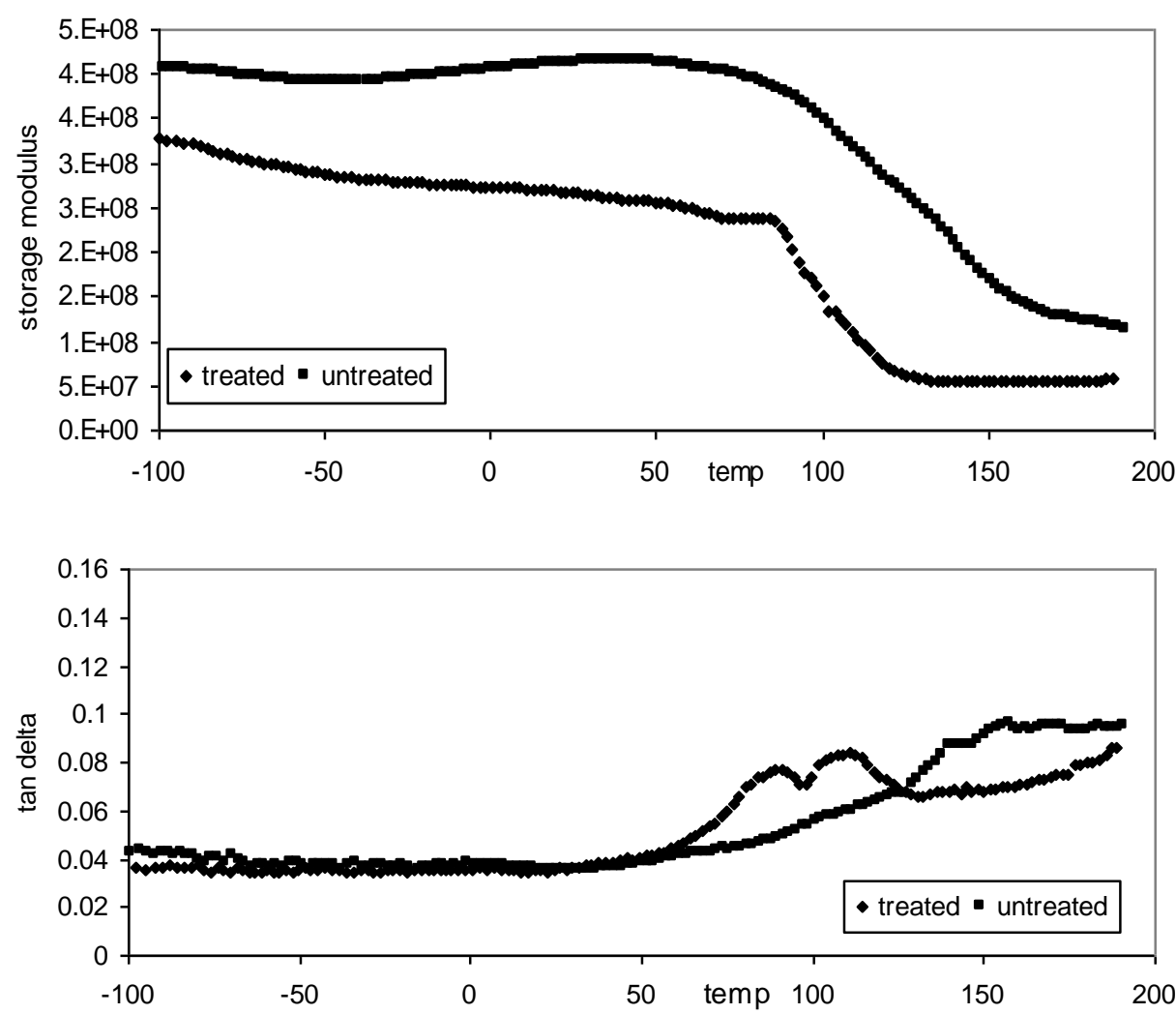

Fig. 8: Storage modulus and tan delta versus temperature for dipterocarpus spp. 

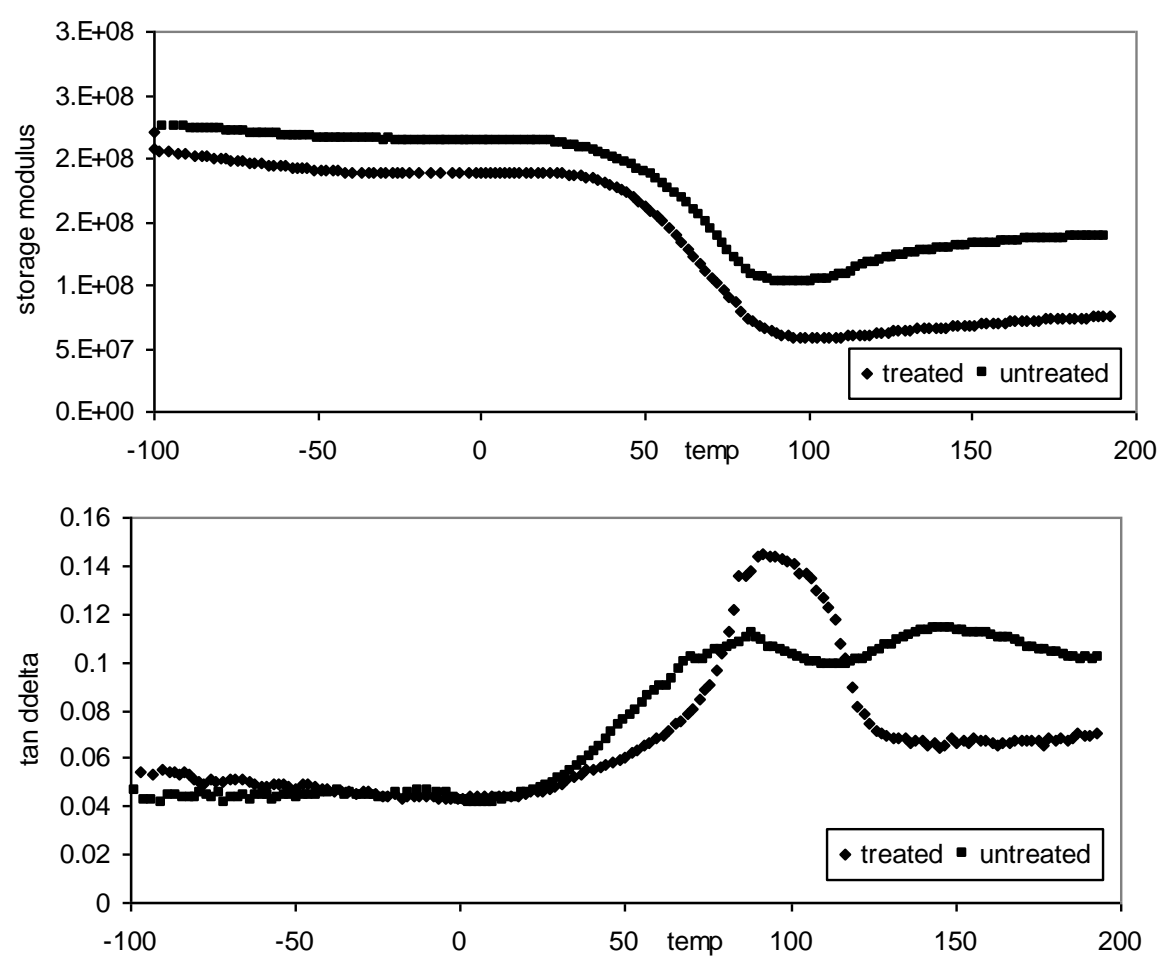

Fig. 9: Storage modulus and tan delta versus temperature for endospermum diadenum.
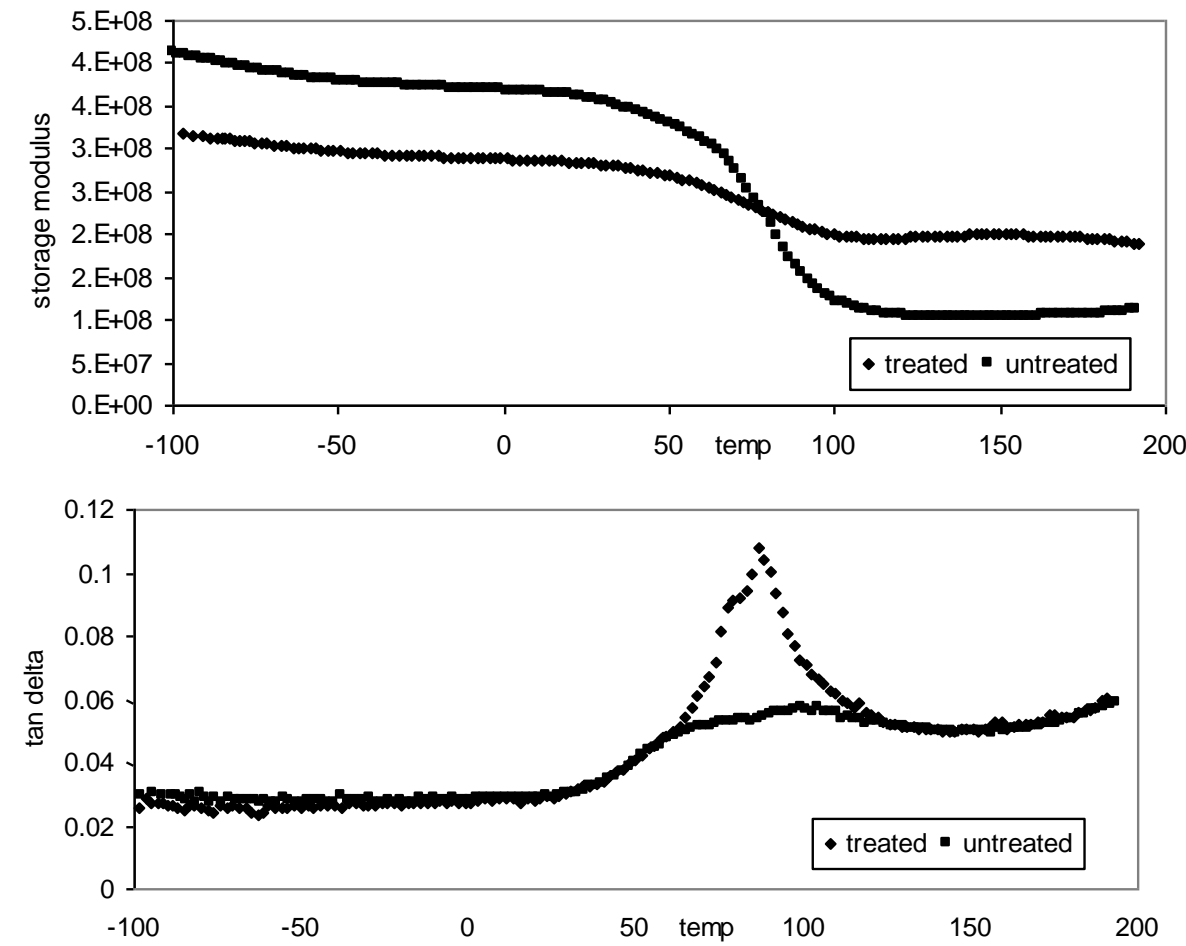

Fig. 10: Storage modulus and tan delta versus temperature for shorea spp. 

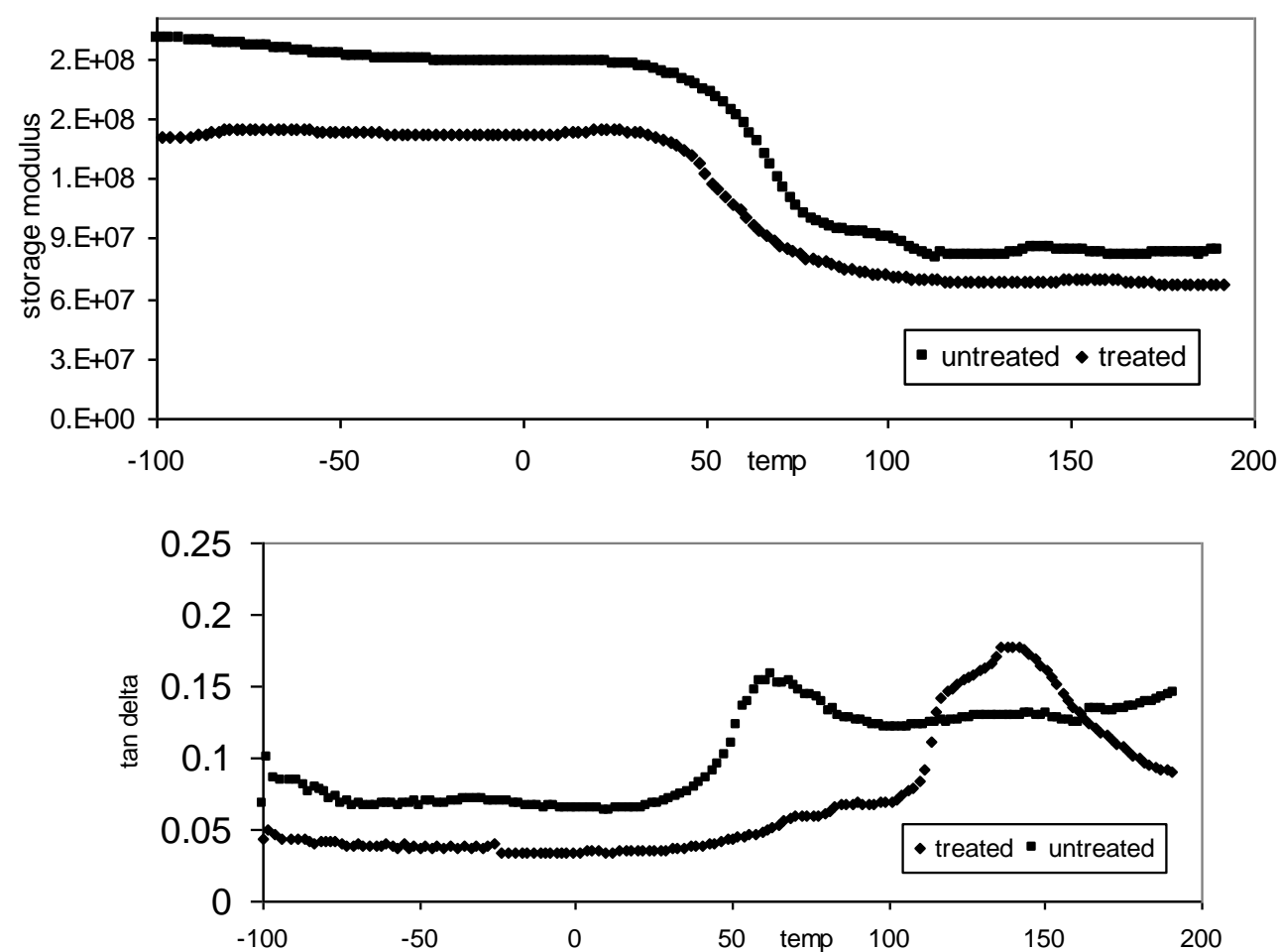

Fig. 11: Storage modulus and tan delta versus temperature for dyera costulata.
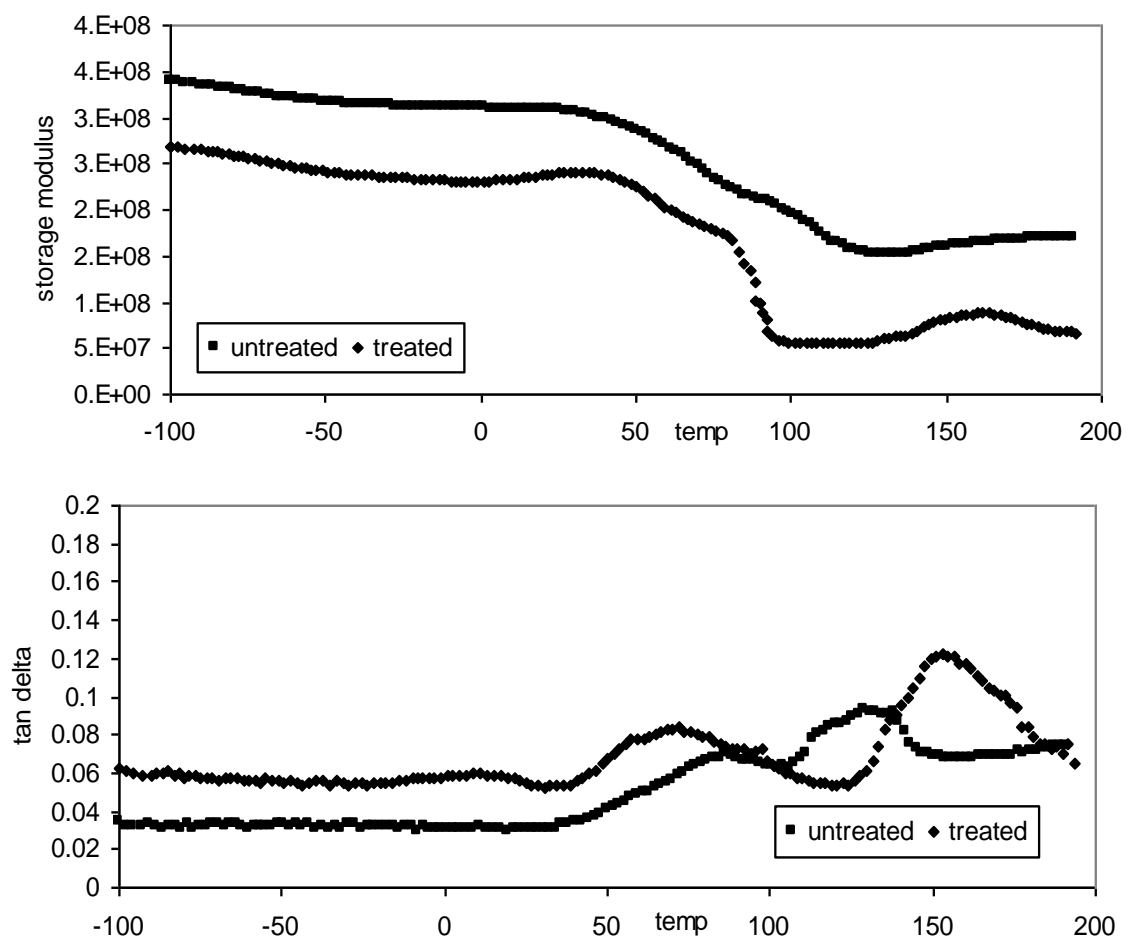

Fig. 12: Storage modulus and tan delta versus temperature for dacrydium spp. 

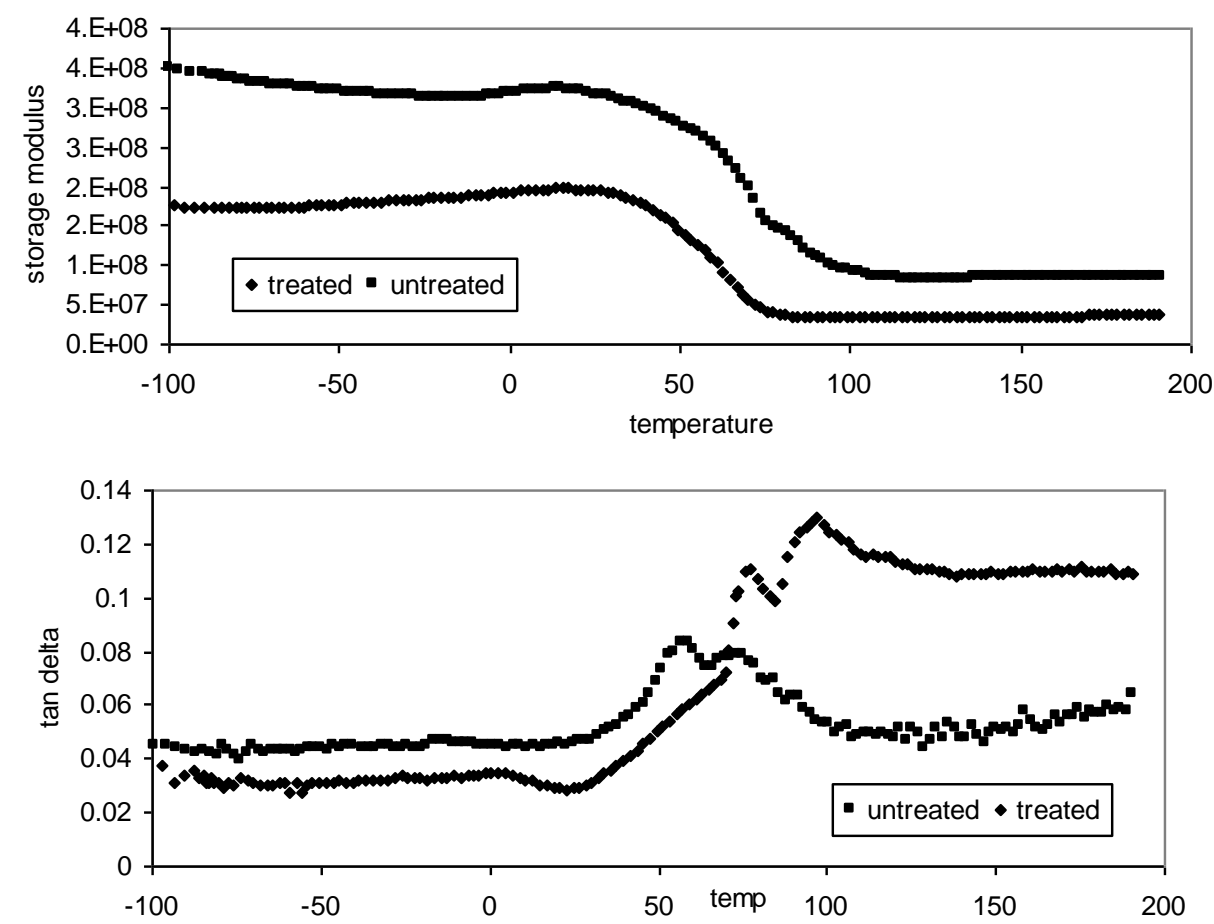

Fig. 13: Storage modulus and tan delta versus temperature for cratoxylum arborescens.

Decreased of E' in plasticized wood is expected at high temperature. The considerable decrease in the value of $\log$ E' from 3.49 to $1.79 \mathrm{MPa}$ for cratoxylum arborescens and 15.2 to $3.37 \mathrm{MPa}$ for shorea macrophylla may mainly results from collapse of the microscopic structure. At $\mathrm{T}_{\mathrm{g}}$, madhuca utilis, shorea gibbosa and shorea spp. displayed a cross over of the E' for treated wood. Although plasticization had lowered the E' values for madhuca utilis, shorea gibbosa and shorea spp but above $T_{g}$ the values are higher than the untreated wood. This indicate plasticization are only effective below $T_{g}$ and had reversed effect above $T_{g}$.

Table 1: $T_{g}$ for treated and untreated.

\begin{tabular}{lll}
\hline Species & $\mathbf{T}_{\mathbf{g}}$ Untreated temp $\left({ }^{\circ} \mathbf{C}\right)$ & $\mathbf{T}_{\mathbf{g}}$ Treated temp $\left({ }^{\circ} \mathbf{C}\right)$ \\
\hline acacia mangium & 100.7 & 87.5 \\
shorea macrophylla & 103.2 & 94.2 \\
madhuca utilis & 59.2 & 69.8 \\
shorea gibbosa & 94.3 & 81.2 \\
dipterocarpus spp & 157.0 & 92.6 \\
endospermum diadenum & 143.0 & 93.6 \\
shorea spp & 97.0 & 86.0 \\
dyera costulata & 139.5 & 62.2 \\
dacrydium spp & 86.3 & 73.8 \\
cratoxylum arborescens & 77.3 & 58.8 \\
\hline
\end{tabular}


Table 1 showed the glass transition temperature, $\mathrm{T}_{\mathrm{g}}$ for treated and untreated wood interpreted from the $\tan \delta$. The $\mathrm{T}_{\mathrm{g}}$ of plasticized wood, except madhuca utilis, where the maximum damping developed decreased with monomer content.

Tan $\delta$ are also influenced by the plasticization in the temperature range of $50-150^{\circ} \mathrm{C}$. Although all species displayed a single transition in the log E' versus temperature, but shorea gibbosa, dacrydium spp and cratoxylum arborescens showed 2 distinct peaks in the $\tan \delta$ versus temperature curves. The remarkable increased in the value of tan $\delta$ may result from collapse of microscopic structure as mention above. Two types of relaxation are detected in the treated shorea gibbosa, dipterocarpus spp, endospermum diadenum and dacrydium spp although the untreated specimens display only one significant relaxation. These relaxations are attributed to the micro Brownian motion of the main chain in the non crystalline region, the motion of the absorbed moisture molecules and the motion of the $\mathrm{CH}_{2} \mathrm{OH}$ group. The micro Brownian motion of the main chain may be restricted to some extent by this cross-linking resulting in a lowering of the first peak $\left(\mathrm{T}_{\mathrm{g}}\right)$ in the treated samples.

\section{CONCLUSIONS}

From the results obtained it is concluded that MMA impregnation and polymerised in situ as showed in Figure 1 (mean retention, \%F) also showed significant plasticizing effect as plasticizer on the viscoelastic behavior in figure 4 - 13. MMA reduced the E' and reduced the $\mathrm{T}_{\mathrm{g}}$. Although different levels of MMA retention are gained, all the wood species are treatable as shown by the non-zero percentage of mean retention $(\% \mathrm{~F})$. The ultrasonic wave in both direction showed that the treatment have significantly increased the density of the wood. In the present works DMTA has identified the changes of $\mathrm{E}^{\prime}$ and $\mathrm{T}_{\mathrm{g}}$ due to the treatment. Most important DMTA had showed that all species become plasticized to certain extent and some species showed two distinct relaxations after the treatment.

\section{REFERENCES}

1. Dirol, D. (1985), Evaluation d'une méthode d'essais mycologiques sur vermiculite. Holzforchung, 39, pp. 11-16.

2. Griffin, D.M. (1977), Water potential and wood decay fungi. Ann. Rev. Phytopathol., 15, pp. 319-329.

3. Langwig, J.E., Meyer, J.A., and Davidson, R.W. (1969), New monomers used in making wood-plastic. Forest Prod. J., 19(11), pp. 57-61.

4. Meyer, J.A. (1981), Wood polymer materials: State of the art. Wood Science, Vol. 14. No., 12 , pp. 49-54.

5. Moore, G.R. (1983), Impregnation of wood with a high viscosity epoxy resin. Wood Fiber Sci., 15, pp. 223-234.

6. Noah, J.N. and Foudjet, A. (1988), Wood science and technology. Wood Sci. Technol., 22, pp. 115-119.

7. Siau, J.F. (1971), Flow in wood. Syracuse Univ. Press. Syracuse, N.Y.

8. Siau, J.F., Meyer, J.A., and Skaar, C. (1965), A review of developments in dimensional stabilization of wood using radiation techniques. Forest Prod. J., 15(4), pp. 162-166.

9. Young, R.A. and Meyer, J.A. (1968), Heartwood and sapwood impregnation with vinyl monomers. Forest Prod. J., 18(4), pp. 66-68. 